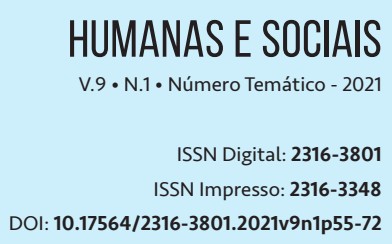

DOI: 10.17564/2316-3801.2021v9n1p55-72
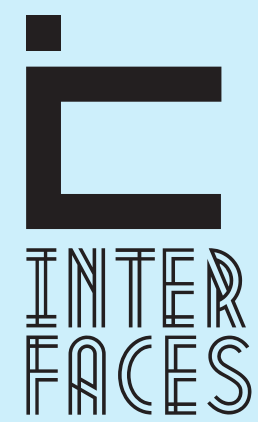

CIENTÍFICAS

\section{PESSOAS COM DEFICIÊNCIA EM MUSEUS DE CIÊNCIA: PERFIL E OPINIÃO DOS VISITANTES ESPONTÂNEOS}

PEOPLE WITH DISABILITIES IN SCIENCE MUSEUMS: PROFILE AND OPINION OF SPONTANEOUS VISITORS

PERSONAS CON DISCAPACIDAD EN MUSEOS DE CIENCIAS: PERFLL Y OPINIÓN DE VISITANTES ESPONTÁNEOS

Andréa F. Costa ${ }^{1}$ Aline R. S. F. Castro ${ }^{2}$

Denise C. Studart ${ }^{3}$

Mônica S. Dahmouche ${ }^{4}$ Wailã S. Cruz ${ }^{5}$

NÚMERO TEMÁTICO:

"DEFICIÊNCIA, ACESSIBILIDADE E DIVULGAÇÃO CIENTÍFICA"

\section{RESUMO}

A discussão em torno da acessibilidade vem crescendo e ganhando espaço nas agendas de discussão de políticas públicas com vistas a garantir à pessoa com deficiência o exercício de seu direito à fruição. Embora estejam crescendo lentamente, ainda são escassos os estudos de público em museus brasileiros e os existentes não contemplam as pessoas com deficiência. 0 presente artigo apresenta uma pesquisa inédita acerca do perfil e da opinião de pessoas com deficiência em situação de visita espontânea a 10 dos museus que integram o Observatório de Museus e Centros de Ciência e Tecnologia (OMCC\&T), nas cidades do Rio de Janeiro e de Duque de Caxias. Foram aplicados 4.705 questionários aos visitantes espontâneos maiores de 15 anos dessas instituições e 63 foram respondidos por pessoas com deficiência. Os respondentes estão distribuídos igualmente quanto ao sexo, a maior parte possui ensino superior completo, característico do público que frequenta museus. Eles consideraram a falta de divulgação e de informações sobre museus e exposições como uma das principais barreiras à visitação. 0 acolhimento pela equipe dos museus foi o único aspecto considerado "ótimo/muito bom" por mais da metade dos pesquisados, evidenciando a importância da acessibilidade atitudinal.

\section{PALAVRAS-CHAVE}

Museus de Ciência. Acessibilidade. Inclusão. Estudos de Público. Pessoa com Deficiência. 


\section{ABSTRACT}

The discussion around accessibility has been growing and gaining space in the public policy discussion agendas with a view to guaranteeing people with disabilities the exercise of their right to enjoyment. Public studies in Brazilian museums on the subject are scarce and the existing ones do not include people with disabilities. This article presents an unprecedented research about the profile and opinion of people with disabilities in a situation of spontaneous visit to ten museums that are part of the Observatory of Museum and Science and Technology Centers - OMCC\&T, in the cities of Rio de Janeiro and Duque de Caxias. At these institutions, a total of 4,705 questionnaires were administered to spontaneous visitors over 15 years of age and 63 of them were answered by people with disabilities. Respondents are equally distributed as to sex; among these, physical disability prevails. Most respondents have completed higher education, characteristic of the public that attends museums. They considered the lack of information about museums and exhibitions as one of the main barriers to visitation. Reception by museum staff was the only aspect considered "very good" by more than half of those surveyed, showing the importance of attitudinal accessibility.

\section{KEYWORDS}

Science Museums, Accessibility, Inclusion, Public Studies, People with Disabilities

\section{RESUMEN}

La discusión sobre accesibilidad ha ido creciendo y ganando espacio en las agendas de discusión de políticas públicas con el fin de garantizar a las personas con discapacidad el ejercicio de su derecho al disfrute. Los estudios públicos en museos brasileños sobre el tema son escasos y los existentes no incluyen a personas con discapacidad. Este artículo presenta una investigación sin precedentes sobre el perfil y la opinión de las personas con discapacidad en una situación de visita espontánea a diez museos que forman parte del Observatorio de Museos y Centros de Ciencia y Tecnología - OMCC๕T, en las ciudades de Río de Janeiro y Duque de Caxias. Se aplicaron 4.705 cuestionarios a los visitantes de estos museos y 63 fueron respondidos por personas con discapacidad. Los encuestados están igualmente distribuidos en cuanto al sexo; entre estos, prevalece la discapacidad física. La mayoría de los encuestados han completado la educación superior, característica del público que asiste a los museos. Consideraron la falta de divulgación e información sobre museos y exposiciones como una de las principales barreras para las visitas. La bienvenida del personal del museo fue el único aspecto considerado "muy bueno" por más de la mitad de los encuestados, destacando la importancia de la accesibilidad actitudinal.

\section{PALAVRAS CLAVE}

Museos de Ciencias, Accesibilidad, Inclusión, Estudios De Público, Personas Con Discapacidad 


\section{INTRODUÇ̄̃̃O}

O acesso universal à cultura é uma das garantias asseguradas pela Declaração dos Direitos Humanos (ONU, 1948, p. 4). Os museus e centros culturais, devido ao seu caráter conceitual de instituições sociais voltadas ao público e enquanto equipamentos de produção da memória, devem oferecer condições de amplo acesso aos seus edifícios, coleções e demais elementos musealizados.

A inclusão social da pessoa com deficiência vem sendo cada vez mais abordada pela sociedade, sobretudo no que se refere à acessibilidade e à equidade de oportunidades em todas as áreas. Sassaki (2009, p. 10) afirma que inclusão:

[...] é o processo pelo qual os sistemas sociais comuns são tornados adequados para toda a diversidade humana - composta por etnia, raça, língua, nacionalidade, gênero, orientação sexual, deficiência e outros atributos - com a participação das próprias pessoas na formulação e execução dessas adequações.

Tornar inclusiva uma sociedade excludente é dever de todos, porém mecanismos legais são necessários para atingir esse objetivo. Nesse sentido, merece destaque a Lei Brasileira de Inclusão (LBI), cujo propósito é assegurar e promover, em condições de igualdade, o exercício dos direitos e das liberdades fundamentais para as pessoas com deficiência (BRASIL, 2015). A LBI é um marco legal para o acesso aos conteúdos culturais e educativos pelas pessoas com deficiência.

No contexto brasileiro, é importante destacar a ratificação da Convenção da Organização das Nações Unidas (ONU), promulgada no Congresso Nacional e incorporada ao texto constitucional. A Convenção é considerada uma referência em relação às pessoas com deficiência e um marco para a construção de políticas públicas da área nas próximas décadas; segundo ela:

[...] a deficiência é um conceito em evolução e que resulta da interação entre pessoas com deficiência e as barreiras devidas às atitudes e ao ambiente que impedem a plena e efetiva participação dessas pessoas na sociedade em igualdade de oportunidade com as demais pessoas (BRASIL, 2009a, on-line).

No meio museal, o Estatuto de Museus prevê no artigo 31 que é essencial promover ações de comunicação para se fazer conhecer os bens culturais incorporados ou depositados no museu, proporcionando o acesso ao público. 0 museu deve ser caracterizado pela acessibilidade universal dos diferentes públicos, seguindo as normas estabelecidas em leis (BRASIL, 2009b).

O Plano Nacional de Cultura recomenda que até 2020 as resoluções das suas normas entrem em vigor (BRASIL, 2012). A meta número 29 trata da acessibilidade e de garantir que as pessoas com deficiência possam ter acesso aos espaços culturais, seus acervos e atividades. Para isso, propõe a adaptação dos espaços físicos e a oferta de bens e atividades em formato acessíveis. Apesar da obrigatoriedade, embasada nos preceitos das diferentes legislações em vigor que se complementam e enfatizam os itens de acessibilidade como observadas na legislação vigente, a maioria dos espaços não é acessível (IBRAM, 2011; ROCHA et al., 2020). 
O conceito de acessibilidade deve ser incorporado por toda a sociedade, incluindo os museus, de forma completa, não se restringindo apenas à superação de barreiras físicas. Para Sassaki (2009), a acessibilidade perpassa por seis dimensões, sendo elas: arquitetônica, comunicacional, metodológica, instrumental, programática e atitudinal. Assim como avaliado por esse autor, entendemos que para alcançarmos uma sociedade menos desigual em termos de acesso à cultura e ao lazer, esses aspectos devem orientar a busca dos espaços culturais por ofertas mais acessíveis, ainda que paulatinamente.

A acessibilidade em museus, do ponto de vista programático, teórico, acadêmico e prático, vem sendo desenvolvida de modo significativo nos últimos anos, embora ainda esteja longe de atingir plenamente as metas desejadas. Apesar da crescente literatura sobre acessibilidade em museus, verifica-se a carência de estudos de público sobre visitantes espontâneos dos museus que deem visibilidade às pessoas com deficiência.

Uma pesquisa realizada em 14 museus nacionais portugueses avaliou os recursos de acessibilidade presentes nessas instituições (audioguias, rampas, maquetes etc.), contudo não gerou informações acerca da presença de visitantes com deficiência (DGPC, 2019). Outra investigação, realizada em 16 museus espanhóis, verificou indiretamente a baixa frequência de pessoas com deficiência a partir da identificação do uso reduzido dos recursos de acessibilidade, uma vez que o questionário usado não contava com qualquer pergunta para levantar dados acerca desse público (LABORATÓRIO, 2011).

O mesmo acontece com o questionário usado para coleta de informações dos visitantes disponibilizado pelo Observatório Ibero-americano de Museus (OIM), do Programa Ibermuseus (IBERMUSEUS, 2018). Contudo, foi possível localizar um estudo realizado entre 2017 e 2018 em 105 museus ingleses que se preocupou em identificar a presença de visitantes com deficiência. 0 resultado mostrou que $10 \%$ dos visitantes afirmavam possuir algum grau de deficiência, sendo que o percentual da população inglesa que possui essa condição corresponde a 18\% (THE AUDIENCE AGENCY, 2018).

Com o intuito de gerar dados acerca do perfil e opinião de pessoas com deficiência entre os visitantes espontâneos de museus de ciência localizados nas cidades do Rio de Janeiro e de Duque de Caxias, o Observatório de Museus e Centros de Ciência e Tecnologia (OMCC\&T) fez alterações em seu instrumento de pesquisa. Assim, em sua rodada mais recente, realizada nos anos de 2017 e 2018, foram obtidos, pela primeira vez, dados acerca dos referidos visitantes.

0 presente artigo apresenta uma discussão inédita acerca do perfil e da opinião de pessoas com deficiência em situação de visita espontânea aos 10 museus participantes da rodada 2017-2018 do OMCC\&T. A partir dos resultados obtidos, busca-se apontar os limites e as potencialidades dos museus de ciência no que se refere à sua atuação como espaços de popularização da ciência junto às pessoas com deficiência.

\section{DIAGNÓSTICO DA ACESSIBILIDADE NOS MUSEUS DE CIÊNCIA PARTICIPANTES DA PESQUISA DO OMCCET}

As experiências que uma visita ao museu proporciona podem ser muitas, mas nem todos podem ter acesso a elas. No cotidiano das pessoas com deficiência que visitam museus, constata-se a presença de 
obstáculos impeditivos para o processo de fruição (FERREIRA, 2011), que vai desde a falta de autonomia para acessar algum espaço até o despreparo de funcionários no atendimento a esse público.

O Guia de Museus e Centros de Ciências Acessíveis da América Latina e do Caribe (ROCHA et al., 2017) apresenta um panorama da acessibilidade em 110 espaços científico-culturais dedicados à popularização da ciência e tecnologia no Brasil e em outros nove países da América Latina e do Caribe. Recorremos ao Guia para construir um panorama da acessibilidade nos museus que integram a rede OMCC\&T. Dos 10 museus que formam o corpus da pesquisa apresentada nesse artigo, sete deles estão apresentados no mesmo, a saber: Espaço Ciência Viva (ECV); Fundação Planetário da Cidade do Rio de Janeiro; Museu Aeroespacial (MUSAL); Museu Ciência e Vida (MCV); Museu da Vida (MV); Museu de Astronomia e Ciências Afins (MAST) e Museu Nacional (MN).

De acordo com o referido Guia, os sete museus citados preenchem, mas não totalmente, vários requisitos relativos à acessibilidade física, tais como: bebedouros e sanitários acessíveis (exceto o MAST); algumas obras, experimentos interativos e equipamentos de exposição em altura acessível para pessoas em cadeira de rodas, com mobilidade reduzida ou de baixa estatura (salvo o MV); locais de reunião, auditórios, cinemas, teatros, planetários acessíveis a pessoas que utilizam cadeira de rodas e/ou com mobilidade reduzida (exceto o ECV).

O Planetário, o MUSAL e o MN são os únicos que possuem vagas de estacionamento reservadas para pessoas com deficiência. Alguns museus oferecem cadeira de rodas ou carrinhos motorizados para uso interno (MUSAL, MCV, MV, MN). Com relação a rampas de acesso, somente o MV não possui, mas oferece plataforma acessível em seu prédio sede. Já o MUSAL e o ECV não dispunham de equipamentos eletromecânicos, elevadores, ou plataformas acessíveis até a data da coleta de informações para o Guia.

Quanto à acessibilidade visual, a maioria dos museus do OMCC\&T estudados nesta pesquisa mencionou que possui alguns equipamentos, experimentos e objetos de exposição que podem ser manipulados/tocados (com exceção do MUSAL). As placas explicativas e os painéis da exposição em braile e/ou pauta ampliada estão presentes em três dos sete museus estudados: Planetário, MAST e MN. O MCV declarou oferecer sessões no Planetário para pessoas com deficiência visual.

Com relação à acessibilidade auditiva, o Planetário e o MUSAL possuem materiais audiovisuais em Libras, enquanto o Planetário e MV oferecem visitas e atividades nessa língua. O ECV e o MAST disponibilizam materiais audiovisuais com legenda em português.

Quanto a outros aspectos de acessibilidade citados, somente o MN mencionou que oferecia um espaço voltado para pessoas com deficiência intelectual e apenas o MUSAL mencionou que o seu site é acessível. Sobre a acessibilidade do entorno, apenas o ECV, o MUSAL e o MN identificaram possuir essa facilidade.

Ainda há muito por ser realizado nos museus brasileiros em termos de desenvolvimento de estratégias para suplantar as barreiras à acessibilidade e garantir a autonomia dos visitantes com deficiência nesses espaços. Mas estamos no caminho. 


\section{PESQUISA PERFIL-OPINIÃO DO OMCCGT: ASPECTOS METODOLÓGICOS}

O presente estudo quali-quantitativo lança mão de uma análise estatística de caráter descritivo. Teve como base a Pesquisa Perfil-Opinião, pesquisa de survey realizada pelo OMCC\&T, rede horizontal, colaborativa, que engloba, por adesão, profissionais e gestores, especialistas ou não dos estudos de público. O OMCC\&T objetiva consolidar informações acerca dos visitantes, das práticas de visitação a museus e centros de ciência, do contexto pessoal e social da visita, bem como das expectativas dos visitantes ao espaço museal. Ademais pretende conhecer também a opinião do visitante sobre os museus.

Os dados que serão tratados neste artigo foram coletados na quarta rodada da Perfil-Opinião, desenvolvida no biênio 2017-2018 nos museus já citados anteriormente e em outros três, a saber: Museu Naval, Jardim Botânico e Museu do Meio Ambiente, os dois últimos pertencentes ao Instituto de Pesquisa Jardim Botânico do Rio de Janeiro. O período de coleta de dados variou entre os museus, embora tenham sido priorizados os meses em que a visitação espontânea é mais expressiva, ou seja, os meses de férias, julho e janeiro, e os fins de semana.

A geração de dados se deu tanto censitariamente quanto por amostragem probabilística, de acordo com o volume de visitantes de cada instituição (KÖPTCKE; CAZELLI; LIMA, 2008). No primeiro caso, todos os visitantes espontâneos maiores de 15 anos que entraram no espaço em dia de coleta de dados e que aceitaram colaborar com a pesquisa responderam o questionário. No segundo caso, foi usada uma seleção sistemática, com intervalo de amostragem de cinco em cinco visitantes e ponto aleatório de partida, assim definida de modo a permitir estimação de médias e variâncias populacionais com pequena margem de erro, mesmo nas tabulações cruzadas. 0 número de questionários varia entre museus, sendo definido de modo que a amostra seja estatisticamente representativa do público da instituição.

O questionário autoadministrado utilizado na pesquisa foi disponibilizado em meio impresso e digital (via tablets) e aplicado de modo a garantir o anonimato dos respondentes. Vinte e oito questões, entre fechadas, semiabertas e uma aberta, foram divididas em quatro blocos, que compreendem o perfil do visitante, os antecedentes e as circunstâncias da visita, a opinião sobre o museu e o hábito de visita a museus.

Todos os dados foram inseridos na base por meio do preenchimento do questionário on-line desenvolvido no software FormSus, disponibilizado pela plataforma DataSus do Ministério da Saúde. Seguindo a Resolução do Conselho-CNS 510/2016, artigo 1º, parágrafo único, inciso I, segundo a qual "Não serão registradas nem avaliadas pelo sistema CEP/CONEP, pesquisas de opinião pública com participantes não identificados" (BRASIL, 2016, on-line), não se fez necessária a submissão desta pesquisa ao Comitê de Ética.

Com vistas a verificar a presença de pessoas com deficiência entre os visitantes espontâneos das instituições participantes, solicitou-se que os pesquisados respondessem à seguinte questão: "Você ou alguém que o acompanha possui algum tipo de deficiência ou outra especificidade?” O respondente possuía três opções de respostas: “Não”; “Eu”; “Acompanhante(s)”. No 
caso daqueles que respondiam a opção “acompanhante(s)", foi perguntado o número de pessoas nessa categoria.

A todos os respondentes, pessoas com deficiência e acompanhantes de pessoas com deficiência, foi solicitado que informassem qual/quais deficiência(s) ou especificidade(s) dos sujeitos envolvidos, ao que eles poderiam responder assinalando uma ou mais das seguintes categorias: Deficiência Física; Cegueira; Baixa Visão; Deficiência Auditiva; Surdocegueira; Deficiência Múltipla; Deficiência Intelectual; Transtorno do Espectro Autista (TEA) e Altas Habilidades/Superdotação.

Os dados das questões fechadas foram conferidos e tabulados por meio do software Microsoft Excel $^{\circledR}$. A questão aberta referente aos comentários e sugestões dos visitantes foi analisada por meio da abordagem bottom-up, que parte de uma análise de conteúdo indutiva das respostas para a mescla progressiva dos registros de mesma natureza, formando conjuntos de respostas mais genéricos (STUDART, 2000).

\section{ACESSANDO OS VISITANTES ESPONTÂNEOS COM DEFICIÊNCIA}

A amostra total da pesquisa realizada pelo OMCC\&T na rodada 2017-2018 é composta por 4.705 questionários. Destes, 63 foram respondidos por pessoas com deficiência. A presença de outros visitantes com deficiência foi identificada por meio das respostas de 115 pesquisados que não possuem deficiência, entretanto informam estar acompanhados de 182 pessoas com deficiência (que não responderam o questionário). No presente estudo apresentamos e analisamos os resultados obtidos junto aos visitantes com deficiência respondentes dos questionários $(\mathrm{N}=63)$.

Em relação a esses respondentes, a análise dos dados gerados revelou um equilíbrio entre os sexos feminino ( $n=33$, em 63 ) e masculino $(n=30$, em 63$)$. As diferentes faixas etárias investigadas também apresentaram equilíbrio entre si, com exceção daquela que vai de 50 a 59 anos (apenas três respondentes em 63). Dos 63 respondentes, 16 informaram ter idade entre "40 a 49 anos", 14 na faixa etária de "15 e 19 anos", seguidos por 12 pessoas com idade entre "30 a 39 anos", e nove indivíduos nas faixas de idade de "20 a 29 anos" e de "60 anos ou mais", em cada uma, respectivamente.

Pessoas com mais de 60 anos são aquelas que usualmente aparecem em menor número entre os visitantes espontâneos de museus, conforme verificado em estudos anteriores do OMCC\&T (KÖPTCKE et al., 2008; KÖPTCKE, 2012; COSTA et al., 2015). Acredita-se que o número de ocorrências de pessoas dessa faixa etária no universo aqui pesquisado - os visitantes espontâneos com deficiência - se deve ao fato da população idosa ser a que tem mais chances de se tornar uma pessoa com deficiência. Em 2010, 67,7\% dos brasileiros com mais de 65 anos possuíam alguma deficiência, sendo de $41,8 \%$ o percentual de pessoas com deficiência severa nessa faixa de idade (OLIVEIRA, 2010).

Entre as pessoas com deficiência que participaram da pesquisa, 53 (em 63) informaram quais deficiências possuem. 0 total de tipos de deficiência é superior ao de sujeitos pesquisados, pois um único indivíduo pode possuir mais de uma deficiência. 
Figura 1 - Distribuição dos tipos de deficiência ou especificidades dos respondentes de acordo com o número de ocorrências

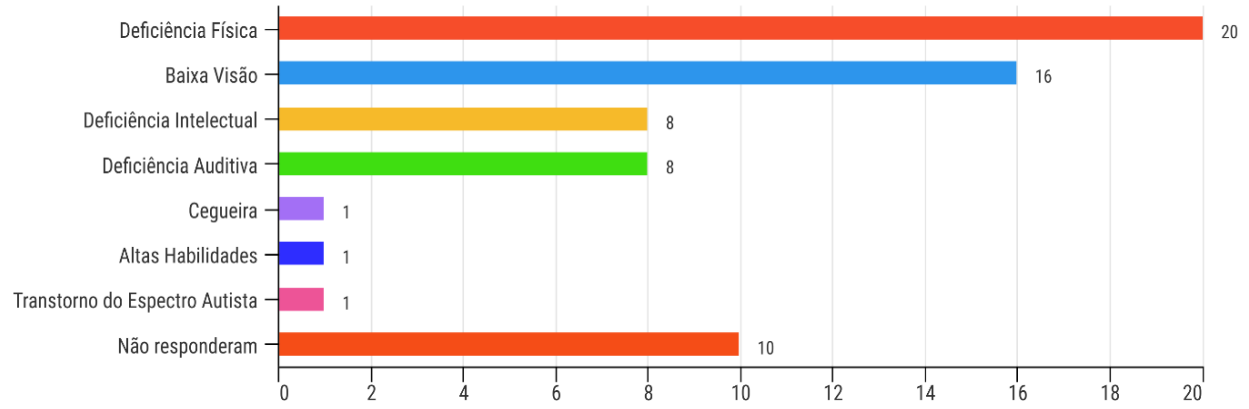

O gráfico de barras horizontais acima demonstra a distribuição dos tipos de deficiência ou especificidades dos respondentes. No eixo vertical estão listados os tipos de deficiência ou espeificidades, de acordo com a maior para a menor ocorrência, no qual a barra vermelha indica 20 ocorrências para Deficiência Física, a azul claro indica 16 para Baixa Visão, a amarela aponta oito ocorrências para Deficiência Intelectual, a verde indica oito para Deficiência Auditiva, a barra lilás indica uma ocorrência para Cegueira, a azul escuro aponta uma para Altas Habilidades e a rosa registra uma ocorrência para Transtorno do Espectro Autista. $\mathrm{Na}$ base do gráfico, a barra laranja indica que 10 pessoas não responderam. No eixo horizontal está apresentado o número de ocorrências, de zero a 20, com intervalos de dois em dois.

Fonte: Dados da pesquisa

Dados do Censo de 2010 mostram que 23,9\% da população brasileira possui algum tipo de deficiência (OLIVEIRA, 2010) ou perda funcional, sendo 8,3\% o percentual da população brasileira que apresenta deficiência de moderada a grave, de caráter permanente, demandando uso de recursos de facilitação (DORNELES et al., 2018). No Censo, o Instituto Brasileiro de Geografia e Estatística (IBGE) mapeou as pessoas com deficiência utilizando as categorias deficiência auditiva, intelectual/mental, motora, visual, pessoas sem declaração de deficiência e com nenhuma dessas deficiências, sendo que as categorias auditiva, motora e visual foram subdivididas em outras três: não consegue de modo algum, grande dificuldade e alguma dificuldade (BRASIL, 2010).

A deficiência visual é a mais frequente entre os brasileiros (18,6\%), seguida pela deficiência motora (7\%), pela deficiência auditiva (5\%) e pela deficiência intelectual (1,4\%) (OLIVEIRA, 2010). No Rio de Janeiro e em Duque de Caxias, onde estão reunidos os museus do OMCC\&T, estão, respectivamente, em média $3 \%$ e $0,5 \%$ das pessoas com deficiência de todo o território nacional. No Rio de Janeiro encontram-se $4,7 \%$ da população nacional que declaram não conseguir enxergar de modo algum (BRASIL, 2010).

Apesar da deficiência visual ser a mais recorrente na população, isso não se reflete de maneira tão significativa no grupo de respondentes. Acreditamos que esse dado tenha relação com o predomínio do sentido da visão, em detrimento de outros sentidos, no contexto das mediações culturais promovidas em equipamentos ainda regidos "pela cultura ocidental, em que predomina a exploração visual, o que leva os visitantes a uma relação superficial com o conteúdo das exposições” (SARRAF, 2015, p. 22). 
O baixo número de ocorrências para algumas deficiências possivelmente resulta da metodologia e dos instrumentos utilizados para a coleta de dados para o estudo. Uma evidência disso é a frequência com a qual outros tipos de deficiência foram informadas por respondentes sem deficiência, mas acompanhados por uma ou mais pessoas com alguma deficiência $(\mathrm{N}=115)$. Do universo total de respondentes sem deficiência, 115 informaram terem feito a visita na companhia de 182 pessoas com deficiência. Destes 115 respondentes, 104 informaram o tipo de deficiência de seus acompanhantes, resultando em 126 ocorrências. Esse número ser superior à quantidade de respostas se deve à possibilidade de um respondente poder estar acompanhado por uma ou mais pessoas com a mesma deficiência ou então por várias pessoas com deficiências diferentes.

Figura 2 - Distribuição dos tipos de deficiência ou especificidades de visitantes que acompanhavam participantes da Pesquisa Perfil-Opinião (2017-2018)

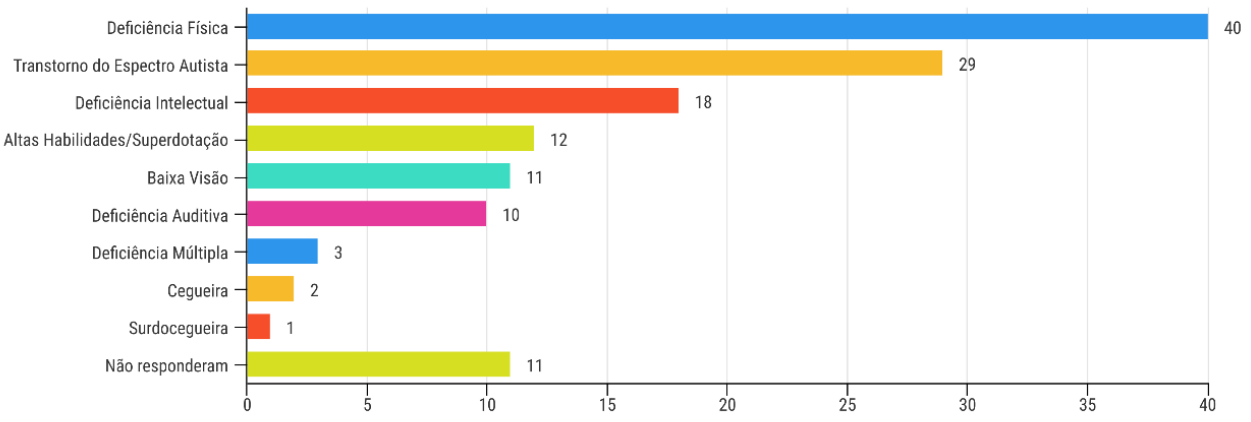

O gráfico de barras horizontais acima demonstra a distribuição dos tipos de deficiência ou especificidades de visitantes que acompanham participantes da Pesquisa Perfil-Opinião (2017-2018). No eixo vertical estão listados os tipos de deficiência ou especificidades, de acordo com a maior para a menor ocorrência, no qual a barra azul indica 40 ocorrências para Deficiência Física, a laranja indica 29 ocorrências para Transtorno do Espectro Autista, a vermelha indica 18 para Deficiência Intelectual, a verde aponta 12 para Altas Habilidades/Superdotação, a azul claro indica 11 ocorrências para Baixa Visão, a rosa 10 para Deficiência Auditiva, a azul aponta três para Deficiência Múltipla, a laranja indica duas ocorrências para Cegueira e a vermelha registra uma ocorrência para Surdocegueira. Na base do gráfico, uma barra verde indica que 11 pessoas não responderam. No eixo horizontal está apresentado o número de ocorrências, de 0 a 40, com intervalos de cinco em cinco.

Fonte: Dados da pesquisa.

Assim como ocorre entre os respondentes com deficiência, a deficiência física é aquela mais frequente entre os acompanhantes dos respondentes que informaram não ter deficiência (FIGURA 2). Contudo, ao contrário do que foi observado entre os primeiros, verificou-se entre os acompanhados com deficiência não só a ocorrência de mais tipos de deficiência como também uma presença mais acentuada de pessoas com Transtorno de Espectro Autista e deficiência intelectual, públicos sobre os quais se detém uma pequena parte dos estudos do campo museal. 
Em relação ao aspecto cor/raça, temos, entre os respondentes, uma maioria de brancos ( $\mathrm{n}=34 \mathrm{em}$ 63), com o hábito de visitar museus - mais da metade deles ( $n=45$ em 63) informou ter visitado ao menos outro museu nos 12 meses anteriores à pesquisa - e 24 (em 63 respondentes) possuem ensino superior completo em diante. Esses dados repetem os resultados de outras pesquisas do OMCC\&T (KÖPTCKE; CAZELLI; LIMA, 2008; KÖPTCKE, 2012; COSTA et al., 2015).

O elevado nível de escolaridade continua sendo uma das principais características dos visitantes de museus e isso se observa, também, entre as pessoas com deficiência, a despeito das dificuldades de acesso desse segmento da população ao ensino superior no Brasil. Há uma década, apenas 6,7\% dos brasileiros com deficiência possuíam ensino superior completo (OLIVEIRA, 2010).

De acordo com dados do Instituto Nacional de Estudos e Pesquisas Educacionais Anísio Teixeira (INEP), 0,5\% dos estudantes matriculados em cursos de graduação no país possuíam algum tipo de deficiência ou necessidade especial. Assim como observado entre os visitantes dos museus, nos cursos de graduação verifica-se, entre os deficientes, uma presença maior de pessoas com deficiência física e baixa visão, respectivamente (INEP, 2019).

Outra similaridade com rodadas anteriores diz respeito ao principal fator que dificulta a visita a museus (FIGURA 3): a falta de divulgação/informação sobre os museus, as exposições, as atividades, dentre outros. Já o segundo aspecto mais citado pelos respondentes com deficiência foi o custo do ingresso. É importante sinalizar que dos 52 respondentes (em 63) que informaram sua renda domiciliar mensal, 25 possuem renda baixa (até 3 salários mínimos), 21 renda média (três a 10 salários mínimos) e apenas seis possuem renda alta (mais de 10 salários mínimos). Dos 10 museus investigados, quatro cobram ingresso, enquanto $80 \%$ dos museus brasileiros não o fazem (IBRAM, 2011).

Apesar da maior parte dos museus ser gratuita e da existência de lei que garante a meia entrada em espetáculos artístico-culturais e esportivos às pessoas com deficiência, bem como aos acompanhantes quando se fizerem necessários (BRASIL, 2013), a cobrança de ingresso é apontada pelos respondentes como um dificultador do acesso a esses equipamentos culturais. Pesquisas estadunidenses e europeias evidenciam que a entrada paga é um dos obstáculos para o acesso de alguns segmentos aos museus (DAWSON, 2014; THE AUDIENCE AGENCY, 2018; SANI, 2018) 
Figura 3 - Fatores que dificultam a visita a museus de acordo com o número de menções feitas pelos respondentes

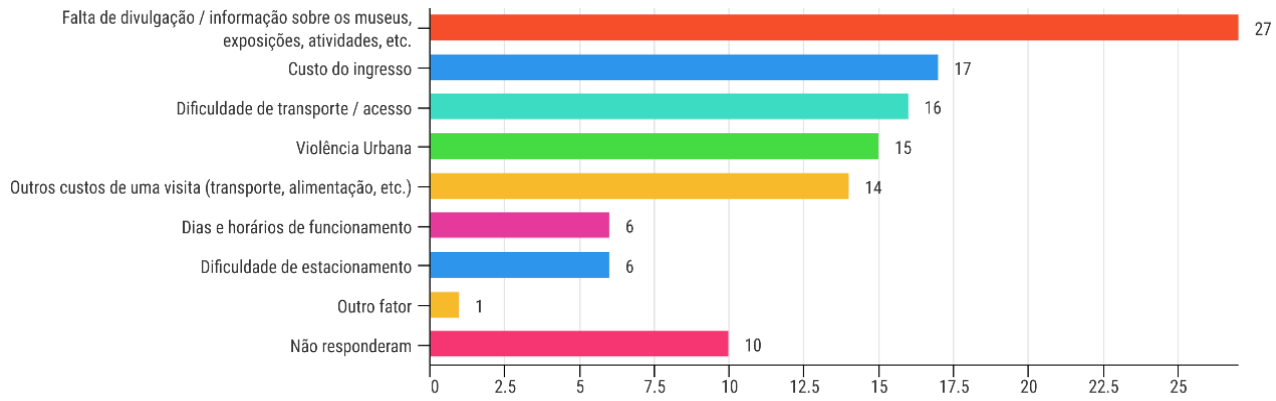

O gráfico de barras horizontais acima demonstra os fatores que dificultam a visita a museus de acordo com o número de menções feitas pelos respondentes. No eixo vertical estão listados os fatores, de acordo com a maior para a menor ocorrência, no qual a barra vermelha indica 27 ocorrências para falta de divulgação/informação sobre os museus, atividades, etc; a barra azul escuro aponta 17 ocorrências para custo do ingresso; a barra azul clara indica 16 para dificuldade de transporte/acesso, a barra verde indica 15 para violência urbana, a barra laranja indica 14 ocorrências para outros custos de uma visita (transporte, alimentação, etc); a barra roxa indica seis ocorrências para dias e horários de funcionamento, a azul indica seis para dificuldade de estacionamento e a barra laranja indica uma ocorrência para outro fator. Na base do gráfico, uma barra rosa indica que 10 pessoas não responderam. No eixo horizontal está apresentado o número de ocorrências, de 0 a 25 , com intervalos de 2,5 em 2,5.

Fonte: Dados da pesquisa.

Em relação às categorias de serviços prestados pelos museus que participaram do estudo - acolhimento, informações, conforto, iluminação e sinalização - observa-se que eles foram avaliados de forma positiva, entre ótimos e bons, conforme pode ser visto na Figura 4. 
Figura 4 - Serviços oferecidos pelos museus - acolhimento, iluminação, informações, sinalização e conforto - segundo avaliação dos respondentes

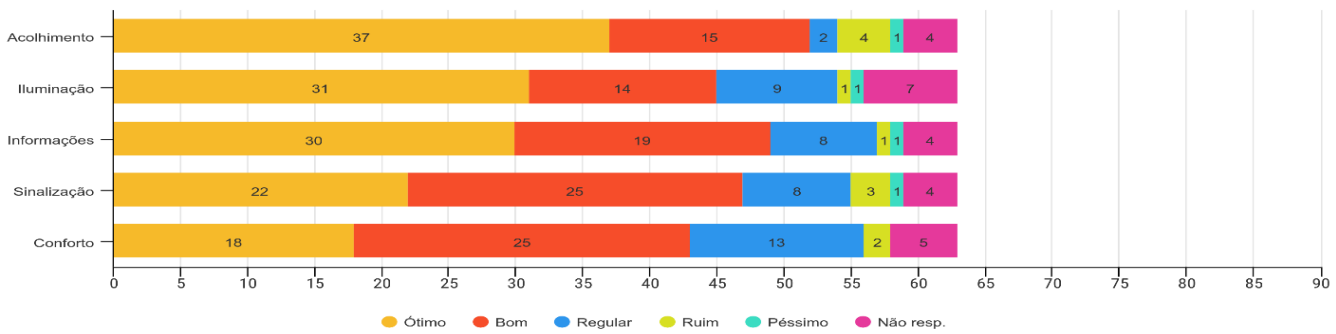

O gráfico de barras horizontais acima demonstra a classificação dos serviços oferecidos pelos museus. No eixo vertical estão listados os tipos de serviço e, no horizontal, da esquerda para direita, estão apresentadas as avaliações, de acordo com o número de ocorrências, de 0 a 85, com intervalos de cinco em cinco. O ótimo é representado pela cor laranja, o bom pela vermelha, o regular pela azul, o ruim pela verde e o péssimo pelo azul claro. Por fim, o rosa indica os que não responderam. $\mathrm{O}$ acolhimento registrou 37 ocorrências para ótimo, 15 para bom, duas para regular, quatro para ruim, uma para péssimo e quatro não responderam. O serviço iluminação registrou 31 ocorrências para ótimo, 14 para bom, nove para regular, uma para ruim, uma para péssimo e sete não responderam. O serviço informações registrou 30 ocorrências para ótimo, 19 para bom, oito para regular, três para ruim, uma para péssimo e quatro não responderam. O serviço sinalização registrou 22 ocorrências para ótimo, 25 para bom, oito para regular, três para ruim, uma para péssimo e quatro não responderam. O conforto registrou 18 ocorrências para ótimo, 25 para bom, 13 para regular, duas para ruim e cinco não responderam.

Fonte: Dados da pesquisa.

Uma análise mais detalhada nos permite reconhecer algumas particularidades. 0 único aspecto considerado ótimo por mais da metade dos pesquisados foi o acolhimento, que compreende a avaliação dos serviços prestados por recepcionistas, monitores, guardas e guias. Esse dado ajuda a evidenciar a importância da acessibilidade atitudinal, que resulta do preparo dos funcionários do museu para o atendimento ao público de pessoas com deficiência e destaca a relevância desses funcionários na recepção do público.

Sassaki (2009) apresenta a dimensão da acessibilidade atitudinal como a ausência de preconceitos, estereótipos, estigmas e discriminações, ou seja, do capacitismo nos comportamentos para com as pessoas que têm deficiência. 0 dado obtido nessa pesquisa reforça a importância dessa dimensão e corrobora os apontamentos de Salasar (2019) acerca da mesma ser destacada pelas pessoas com deficiência como sendo a principal ação de inclusão.

As categorias "Iluminação" e "Informações e explicações disponíveis", sendo essa última composta por painéis, textos, audioguias, filmes etc., receberam avaliações semelhantes. Embora a qualidade dos recursos relacionados à comunicação não deva ser subestimada, as duas categorias estão relacionadas, pois a iluminação influencia diretamente no acesso às informações contidas nas exposições, aos informes e às orientações do museu, fatores fundamentais para autonomia durante a visita, principalmente para as pessoas com baixa visão. Essas categorias podem ser relacionadas às dimensões da acessibilidade instrumental e comunicacional, mencionadas por Sassaki (2009). 
O "conforto", que engloba banheiro, guarda volume, temperatura nas salas, assentos, bebedouros, lanchonete, foi o conjunto de serviços mais mal avaliado. No entanto, os referidos aspectos se relacionam com aqueles contemplados pela acessibilidade arquitetônica, dimensão apontada pelos museus como a mais presente em suas instituições (ROCHA et al., 2020). A discrepância entre o que os museus e os visitantes afirmam pode acontecer devido ao fato da acessibilidade ainda não estar totalmente contemplada em todos os setores dos museus, de uma maneira orgânica.

Entre os que responderam sobre o nível de satisfação com a visita ( $N=58)$, a maioria se mostrou muito satisfeita $(n=32$, em 58$)$ e satisfeita $(n=20$, em 58$)$, enquanto cinco (em 58 ) assinalaram a opção "muito insatisfeito" e um (em 58) assinalou "pouco satisfeito". Dos 55 que responderam à questão sobre um possível retorno ao museu visitado, 27 disseram que pretendem retornar, 18 afirmaram que provavelmente voltarão, nove disseram que não sabiam se retornariam e um afirmou que não voltará.

Os respondentes com deficiência $(\mathrm{N}=63)$ fizeram 32 registros referentes a sugestões e comentários sobre suas visitas. Dentre os registros feitos, se destacaram elogios ao museu/atividade/ geral ( $n=12$, em 32). A necessidade de se ampliar a acessibilidade, com piso tátil, audioguia etc., esteve presente em quatro registros (em 32). Outros aspectos citados foram: melhorias a fazer (manutenção, consertos etc.) ( $n=3$, em 32); mais divulgação/visibilidade ( $n=3$, em 32); entorno (policiamento, transporte) ( $n=3$, em 32 ) e sugestões de atividades, tais como investimento em divulgação do museu, melhorar a acessibilidade para pessoas com limitações de locomoção e disponibilizar mais tradutores e intérpretes de libras.

\section{CONSIDERAÇÕES FINAIS}

0 presente estudo vem preencher uma lacuna existente, tanto na esfera nacional como na internacional, nas pesquisas de público em museus de ciência e na visitação da pessoa com deficiência aos museus. Por meio dele, foi possível verificar a baixa frequência desse segmento entre os visitantes espontâneos das instituições participantes. Tal dado resulta do longo período de exclusão à educação, à cultura, ao trabalho, dentre outros, ao qual as pessoas com deficiência vêm sendo submetidas.

A forma como os museus se comunicam ainda hoje apresenta barreiras que dificultam o acesso ou causam ruído na mensagem, o que é suficiente para que ela não seja compreendida ou que o acúmulo de experiências ruins provoque a desistência de frequentar ambientes como esses. Por outro lado, foi observada na presente investigação que as pessoas com deficiência que visitaram os museus de ciência estudados se mostraram satisfeitas com o acolhimento dos funcionários, demonstrando que a acessibilidade atitudinal, por meio de um bom atendimento prestado pela equipe dos museus, pode contribuir para o retorno do visitante com deficiência.

A despeito disso, a literatura aponta que as dimensões comunicacional e atitudinal vêm sendo preteridas pelos museus em comparação com os recursos de acessibilidade física, o que se reflete em um acesso maior de pessoas com deficiência física a essas instituições em relação àquelas com deficiência visual e auditiva, por exemplo. 
Mais do que quantificar a frequência das visitas, este estudo possibilitou conhecer o perfil das pessoas com deficiência que visitam espontaneamente os museus pesquisados, bem como as opiniões destas acerca de suas experiências nas referidas instituições. Deste modo, com os achados desta pesquisa esperamos contribuir para o delineamento de futuras ações voltadas à promoção da divulgação e popularização da ciência junto a esse segmento do público.

\section{AGRADECIMENTOS}

Aos gestores do Museu do Meio Ambiente, da Fundação Jardim Botânico do Rio de Janeiro, do Museu Naval e do Museu Aeroespacial, que autorizaram o uso dos dados coletados em suas instituições no presente artigo. A Patrícia Lameirão, pelas valiosas discussões sobre o tema. A Ana Maria Amorim Correia, Técnica em Divulgação Científica da Fundação CECIERJ, pela revisão do texto.

\section{REFERÊNCIAS}

BRASIL. Ministério da Saúde. Conselho Nacional de Saúde. Resolução n 510, de 7 de abril de 2016. Dispõe sobre as normas aplicáveis a pesquisas em Ciências Humanas e Sociais. Diário Oficial [da] República Federativa do Brasil, Brasília: DF, 24 maio 2016. Disponível em: http://conselho.saude. gov.br/resolucoes/2016/Reso510.pdf. Acesso em: 11 dez. 2020.

BRASIL. Lei no 13.146, de 6 de julho de 2015. Lei Brasileira de Inclusão da Pessoa com Deficiência, 2015. Brasília: DF: Presidência da República, 2015. Disponível em: http://www.planalto.gov.br/ ccivil_03/_Ato2015-2018/2015/Lei/L13146.htm. Acesso em: 27 jul. 2020.

BRASIL. Lei n. 12.933, de 26 de dez. de 2013. Dispõe sobre o benefício do pagamento de meia-entrada para estudantes, idosos, pessoas com deficiência e jovens de 15 a 29 anos comprovadamente carentes em espetáculos artístico-culturais e esportivos, e revoga a Medida Provisória n² 2.208, de 17 de agosto de 2001. Brasília: DF: Presidência da República, 2013. Disponível em: http://www.planalto.gov.br/ccivil_03/_Ato2011-2014/2013/Lei/L12933.htm Acesso em: 10 jul. 2020.

BRASIL. As metas do plano nacional de cultura. Coordenação geral do Plano Nacional de Cultura. Ministério da Cultura. São Paulo: Instituto Via Pública; Brasília: MinC, 2012. 216p.

BRASIL. Decreto n 6.949, de 25 de agosto de 2009. Promulga a Convenção Internacional sobre os Direitos das Pessoas com Deficiência e seu Protocolo Facultativo, assinados em Nova York, em 30 de março de 2007. Brasília: DF: Presidência da República, 2009a. Disponível em: http://www.planalto. gov.br/ccivil_03/_ato2007-2010/2009/decreto/d6949.htm. Acesso em: 27 jul. 2020. 
BRASIL. Lei n⿳0 11.904, de 14 de janeiro de 2009. Institui o Estatuto de Museus e dá outras providências. Brasília: DF: Presidência da República, 2009b. Disponível em: http://www.planalto. gov.br/ccivil_03/_Ato2007-2010/2009/Lei/L11904.htm. Acesso em: 27 jul. 2020.

COSTA, A. F.; DAMICO, J.S.; GONÇALVES, M.; CAZELLI, S.; MANO, S. CRUZ, W. S. Museus de ciência e seus visitantes: pesquisa perfil-opinião 2013. Rio de Janeiro: Fundação Oswaldo Cruz; Casa de Oswaldo Cruz; Museu da Vida, 2015.

DAWSON, E. Equity in informal science education: developing an access and equity framework for science museums and science centres. Studies in Science Education, v. 50, n. 2, p. 209-247, 2014.

DGPC. Direção-Geral do Património Cultural. Estudo de Públicos de Museus Nacionais Públicos do Museu Nacional de Etnologia. Lisboa: DGPC, 2019. Disponível em: http://www. patrimoniocultural.gov.pt/static/data/museus_e_monumentos/estatisticas_de_2018/mne_ report_032019.pdf. Acesso em: 20 jul. 2020

DORNELES, P. S.; CARVALHO, C. R. A. de; SILVA, A. C. C.; MEFANO, V. Do direito cultural das pessoas com deficiência. Revista de Políticas Públicas, v. 22, n. 1, p. 137-154, 2018.

FERREIRA, A. F. B. C. Dedos de ver: informação especial no museu e a inclusão social da pessoa com deficiência visual. 2011, 151 f. Dissertação (Mestrado) - Programa de Pós-Graduação em Museologia e Patrimônio, Museu de Astronomia e Ciências Afins, Universidade Federal do Estado do Rio de Janeiro, Rio de Janeiro, 2011.

\section{IBERMUSEUS. Sistema de coleta de dados de público de museus do Observatório Ibero-}

americano de Museus. Madrid: Programa Ibermuseos-Observatorio Iberoamericano de Museos, 2018. Disponível em: http://www.ibermuseos.org/wp-content/uploads/2018/07/sistema-coletadados-pt-es.pdf. Acesso em: 19 jul.2020.

IBGE - Instituto Brasileiro de Geografia e Estatística BRASIL. Cidades. 2010. Disponível em: https:// cidades.ibge.gov.br/brasil/rj/rio-de-janeiro/pesquisa/23/23612?detalhes= trueqlocalidade1=33017 0\&localidade2=0. Acesso em: 20 jun. 2020.

IBRAM - Instituto Brasileiro de Museus. Museus em números. Brasília: IBRAM, 2011. Vol.1.

INEP - Instituto Nacional de Estudos e Pesquisas Educacionais Anísio Teixeira. Sinopse Estatística da Educação Superior 2018. Brasília: INEP, 2019.

KÖPTCKE, L. S.; CAZELLI, S.; LIMA, J. M. Museus e seus visitantes: relatório de pesquisa PerfilOpinião 2005. Brasília: Gráfica e Editora Brasil, 2008. 
KÖPTCKE, L. S. (coord.). Pesquisa Perfil-Opinião 2009: museus do Rio de Janeiro 2009. Brasília: Fundação Oswaldo Cruz; MAST/ENCE, 2012.

LABORATORIO Permanente de Público de Museos. Subdirección General de Museos Estatales. Conociendo a nuestros visitantes - Estudio de público en museos del Ministerio de Cultura. Madrid: Secretaría General Técnica Subdirección General de Documentación y Publicaciones, 2011. Disponível em: http://www.ibermuseos.org/wp-content/uploads/2020/04/conociendo-a-nuestrosvisitantes.pdf. Acesso em: 19 jul. 2020

OLIVEIRA, Luiza Maria Borges (org.). Cartilha do Censo 2010 - Pessoas com Deficiência. Secretaria de Direitos Humanos da Presidência da República (SDH/PR). Brasília: SDH-PR/SNPD, 2012. 32 p. Disponível em: https://inclusao.enap.gov.br/wp-content/uploads/2018/05/cartilha-censo-2010pessoas-com-deficienciareduzido-original-eleitoral.pdf. Acesso em: 27 jul. 2020.

ONU - Organização das Nações Unidas. Declaração Universal dos Direitos Humanos. 1948. Disponível em: https://www.unicef.org/brazil/declaracao-universal-dos-direitos-humanos. Acesso em: 27 dez. 2020.

ROCHA, J. N.; MASSARANI, L.; GONÇALVES, J.; FERREIRA, F. B.; DE ABREU, W. V.; MOLENZANI, A. O.; INACIO, L. G. B. (org.). Guia de Museus e Centros de Ciências Acessíveis da América Latina e do Caribe. Rio de Janeiro: Museu da Vida; Casa de Oswaldo Cruz; Fiocruz: RedPOP; Montevidéu: Unesco, 2017.

ROCHA, J. N.; MASSARANI, L.; ABREU, W. V. de; INACIO, L. G. B.; MOLENZANI, A. O. Investigating accessibility in Latin American science museums and centers. Anais da Academia Brasileira de Ciências, Rio de Janeiro, v. 92, n. 1, 2020.

SALASAR, D. N. Um museu para todos: manual para programa de acessibilidade. Pelotas: Ed. da UFPel, 2019.

SANI, M. L'accessibilité au patrimoine: les musées, les communautés et la participation. La ConvèntionCadre - Sur la valeur du patrimoine culturel pour la société. Strasbourg: Conseil de L'Europe, 2018. Disponível em: https://rm.coe.int/serie-d-actualites-de-la-convention-de-faro-l-accessibilite-aupatrimo/16808c26d0. Acesso em: 20 dez. 2020.

SARRAF, V. P. Acessibilidade em espaços culturais: mediação e comunicação sensorial. São Paulo: EDUC: FAPESP, 2015. 
SASSAKI, R.K. Inclusão: acessibilidade no lazer, trabalho e educação. Revista Nacional de Reabilitação (Reação), São Paulo, Ano XII, p. 10-16, mar./abr. 2009.

STUDART, D. C. The perceptions and behaviour of children and their families in child-oriented museum exhibitions. 2000. Tese (Doutorado) - Institute of Archaeology, Museum and Heritage Studies, University College London, Londres, 2000.

THE AUDIENCE AGENCY. Museums Audience Report: what Audience Finder says about audiences for Museums, nov. 2018. Disponível em: https://www.theaudienceagency.org/asset/1995. Acesso em: 20 dez. 2020. 
1 Doutoranda em Educação - PPGEdu/UNIRIO; Professora da Escola de Museologia, Universidade Federal do Estado do Rio de Janeiro - UNIRIO; Educadora Museal, Museu Nacional, Universidade Federal do Rio de Janeiro - UFRJ. E-mail: andrea@mn.ufrj.br

2 Doutora em Geologia - UFRJ; Museóloga, Museu da Geodiversidade - IGEO/UFRJ.

E-mail: alinecastro@igeo.ufrj.br

3 PhD em Museum Studies - UCL; Pesquisadora, Museu da Vida, COC/Fiocruz, Núcleo de Estudos de Público e Avaliação em Museus - NEPAM.

E-mail: denise.studart@fiocruz.br

4 Doutora em Física - USP-SC Fundação Centro de Ciências e Educação Superior a Distância, Fundação Cecierj Museu Ciência e Vida. E-mail: monicacecierj@gmail.com 5 Pós-graduado em Divulgação da Ciência, Tecnologia e Saúde, Museu da Vida/COC/Fiocruz; Astrônomo, Fundação Planetário da Cidade do Rio de Janeiro.

E-mail: waila.cruz@planetario.rio.rj.gov.br

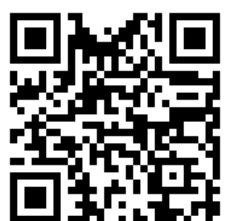

A autenticidade desse artigo pode ser conferida no site https://periodicos. set.edu.br

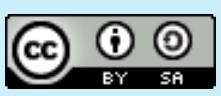

Este artigo é licenciado na modalidade acesso abertosob a Atribuição-Compartilhalgual CC BY-SA

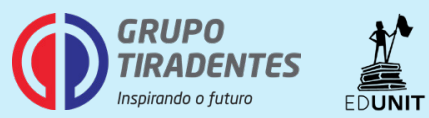

